Research Article

\title{
Impact Tensile Behaviors of PVDF Building Coated Fabrics
}

\author{
Lianqiong Zheng $\mathbb{D}^{1,2}$ Yilong Ye $\mathbb{D}^{1},{ }^{1}$ Jinping zhuang $\mathbb{D},,^{1,2}$ and Yongqian Zheng $\mathbb{D}^{1,2}$ \\ ${ }^{1}$ School of Civil Engineering, Fujian University of Technology, Fuzhou 350118, China \\ ${ }^{2}$ Fujian Provincial Key Laboratory of Advanced Technology and Informatization in Civil Engineering, Fuzhou 350118, \\ Fujian Province, China \\ Correspondence should be addressed to Lianqiong Zheng; zhenglianqiong@163.com
}

Received 28 January 2020; Revised 9 September 2020; Accepted 8 October 2020; Published 30 October 2020

Academic Editor: Payam Shafigh

Copyright (c) 2020 Lianqiong Zheng et al. This is an open access article distributed under the Creative Commons Attribution License, which permits unrestricted use, distribution, and reproduction in any medium, provided the original work is properly cited.

\begin{abstract}
The paper presents the impact tensile behaviors of two common building membranes (Ferrari 1002T2 membrane and XYD $300 \mathrm{~N}$ membrane) in PVDF-coated-fabric membrane structures. The tests are conducted using the split Hopkinson bar test device. Typical forms of stress and strain are applied for comparing the stress-strain relationship between quasi-static and high strain rates. Besides, the failure mechanism and energy absorption at high strain rates are discussed. The results show that with the increase of strain rates, the growth rate of the stress of PVDF membrane decreases gradually, which is different from the stress-strain relationship in low strain rates. At high strain rates, the ultimate tensile strength increases linearly with the increase of strain rates. In addition, the energy absorption capacity of the material increases with the increase of strain rates. The results can provide an important basis for the design and analysis of membrane structures under the impact loads.
\end{abstract}

\section{Introduction}

As a new form of large-span spatial structures, membrane structures are often used in the construction of large public buildings such as stadiums and exhibition centers. The membrane structure is pretensioned to maintain the shape and bear the load [1]. However, under the wind-induced disaster, the membrane structure is often impacted by the fragments rolled up by the strong wind, including glass, stone, and metal [2]. These wind-induced fragments impact the membrane surface at a higher rate, resulting in a gap in the membrane surface [3]. Then, under the wind load, the tearing failure occurs easily, and the crack propagates fast, resulting in the overall damage of the structure (Figure 1).

At present, considerable progress has been made in the research of structural theory, including form-finding analysis, cutting analysis, and load state analysis, as well as the development of calculation and software analysis [4]. Accordingly, as another important factor to study the performance of membrane structures and ensure the safety of membrane structures, research on the properties of membrane materials is still lacking behind [5].

At present, the research on membrane materials is mainly focused on the quasi-static tests. The main mechanical properties of membrane materials have been studied systematically, such as the uniaxial tensile test, the biaxial tensile test, the tear test, and the creep test [6]. Some researchers have done a lot of research on the failure mechanism and constitutive relationship of building membrane materials [7-9]. Some researchers have done a lot of research on the micro performance of PVDF membrane materials [10-14]. Dinh et al. [15] analyzed the tension fabric membrane structure used in foldable architectural applications using nonlinear finite elements, which was validated with the experimental data obtained from digital image correlation (DIC) technique. Ambroziak and Klosowski performed uniaxial and biaxial tests based on the least squares technique and proposed a method of laboratory tests necessary for the identification of mechanical properties of the coated fabric [16]. 


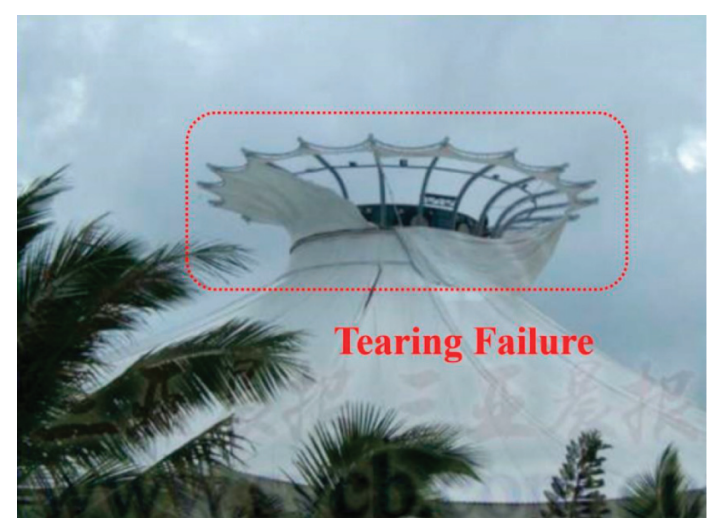

FIgURe 1: Postfailure cultural exhibition center in Sanya.

In the study of dynamic response of membrane structures, Wang et al. [17] studied the mechanical behavior of plain woven fabrics under high-strain-rate lateral impact using the finite element method. Besides, the impact test of single-layer plates is carried out under the same fabric structure and loading conditions, which showed good agreement with the FE results. Some researchers have studied the dynamic response of membrane structures under impact load and analyzed the parameters of boundary conditions, membrane prestress, and alluvial velocity $[3,18-20]$. Some researchers have studied the dynamic response of circular thin membranes under low velocity impact loading and discussed the dynamic response law of forced vibration of thin membranes under different initial conditions and material parameters [21, 22]. Ma et al. [23] analyzed mechanical properties of CWKF composites at different strain rates from the point of view of frequency domain. Jain [24] studied the impact of wind-induced fragments on high-rise glass and considered the effect of impact velocity. Ross et al. [25] studied the failure mode of metal roof under the impact of wind-induced fragments and explained the failure mechanism. Zhao et al. [26] and Zhang et al. [27] studied the dynamic mechanical properties of PVC membranes from the perspective of failure mode and frequency domain.

When textile structural composites are subjected to quasi-static loads, the force has sufficient time to transfer in the fiber and matrix until the final state. Nevertheless, when the material is subjected to high-strain-rate stress, the situation will change significantly. Because the load propagates rapidly in the material, there is less time for stress wave to be completely transferred in the material. Because of the distribution of fiber and matrix in the material, the effect of stress wave on each part of the material is also completely different and unclear.

Referring to the current research results, it can be found that the research on membrane structures mainly focuses on the mechanical properties and response analysis of materials and structures under quasi-static and the impact loads. However, there are few studies on the mechanical properties of building membrane materials under high strain rates. In the current design of membrane structures, the mechanical properties of the material under quasi-static are taken as design basis. For example, according to the relevant design specifications, the common rate of the tensile test is $100 \mathrm{~mm} /$ min when the tensile strength value needs to be determined. However, as coated fabric composites, the mechanical properties of membrane materials under high strain rates are not clear, which is important for the response of membrane structures under impact. In order to deeply study the accurate response of membrane structures under wind-induced disasters, it is necessary to further study the mechanical properties of membrane materials under high strain rates and the impact resistance of membrane structures.

In this paper, two common building membrane materials, Ferrari 1002T2 membrane and XYD 3000N membrane, are chosen as the research object. The stress-strain relationship between high strain rates and quasi-static is discussed, and the failure mechanism and energy absorption are studied. The variations of mechanical property parameters under different strain rates are analyzed, including ultimate strength, Young's modulus, energy absorption, and so on. The results can provide an important basis for the design and analysis of membrane structures under the impact loads.

\section{Experimental Procedure}

2.1. Materials. Two kinds of coated fabrics were selected for mechanical analysis. One is XYD $3000 \mathrm{~N}$, a typical PVCcoated fabrics with the thickness of $0.65 \mathrm{~mm}$ and the density of $850 \mathrm{~kg} / \mathrm{m}^{3}$. The other one is Ferrari 1002T2 (PVDF), with the thickness of $0.78 \mathrm{~mm}$ and the density of $1050 \mathrm{~kg} / \mathrm{m}^{3}$. Figure 2 shows the dimensions and microscopic structure of PVC/PVDF-coated fabrics studied in this paper. Due to the different weaving process, under normal circumstances, the warp and weft direction of the membrane material show the difference in tensile strength.

2.2. Tensile Tests under Various Strain Rates. In this part, test schemes of quasi-static tests and high-strain-rate tests are introduced, and the measuring principle and equipment of high-strain-rate tests are explained in detail.

2.2.1. Quasi-Static Tests. The rates of tensile tests under quasi-static are 1,10 , and $100 \mathrm{~mm} / \mathrm{min}$. The tensile tests of warp and weft specimens were carried out respectively. Considering the size of the specimen, the strain rate under quasi-static can be calculated according to the following formula:

$$
\dot{\varepsilon}=\frac{v}{l}
$$

where $\dot{\varepsilon}$ is the approximate strain rate, $v$ is the tensile rate, and $l$ is the length of the specimen.

2.2.2. High-Tensile-Velocity Tests. The wind-induced fragment velocity is in the range from $30 \mathrm{~m} / \mathrm{s}$ to $50 \mathrm{~m} / \mathrm{s}$, and the strain values of $350,500,750,900$, and $950 \mathrm{~s}^{-1}$ are taken as the five loading conditions. In this paper, the impact tensile 


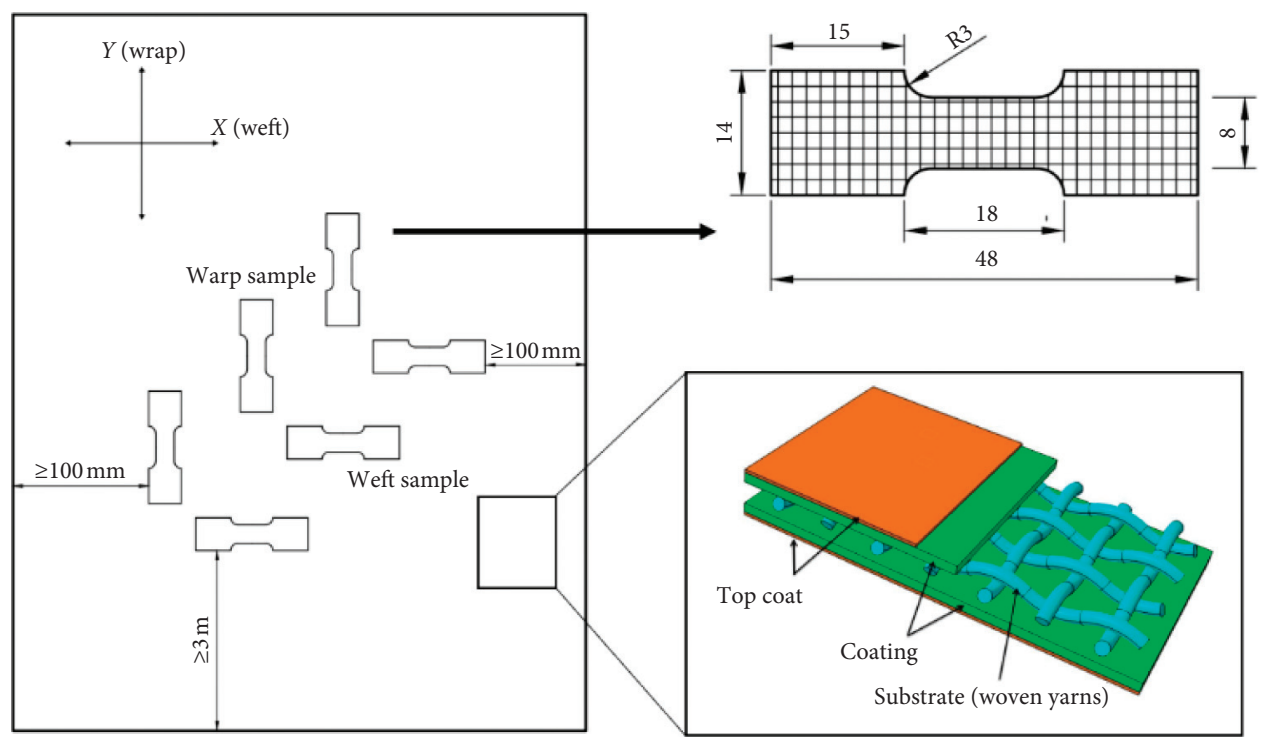

FIGURE 2: Diagram of cutting size and composition of the specimen.

test device is used to study the impact tensile mechanical properties of PVC/PVDF membrane specimens using the split Hopkinson tension bar device, and it is shown in Figure 3. The test device is mainly composed of a launch system, bar system, and data processing system. In order to complete the test as accurately as possible, the adhesive mode between the specimen and the bar is adopted. The advantage of this method over the wedge extrusion system is that there is no stress concentration at the edge of the clamp. The adhesive is made of DP810 two-component epoxy adhesive from 3M Company.

According to the one-dimensional elastic stress wave theory, the stress of the specimen can be calculated:

$$
\sigma=E \varepsilon_{\mathrm{t}} \frac{A_{\mathrm{b}}}{A_{\mathrm{s}}},
$$

where $E$ is the elastic modulus of the transmission bar; $E_{\mathrm{t}}$ is the strain of the transmission bar; $A_{\mathrm{b}}$ is the cross-sectional area of the elastic bar; and $A_{s}$ is the cross-sectional area of the specimen core.

\section{Results and Discussion}

3.1. Failure Modes. The typical failure modes under different strain rates are shown in Figure 4. There are three main failure modes. For the first mode (damage mode), the specimen do not break completely. According to the statistical data, it can be found that the failure mode corresponds to the rate range from $350 \mathrm{~s}^{-1}$ to $500 \mathrm{~s}^{-1}$. For the second mode (single fracture mode), the failure form of the specimen approximately shows a flat port, which corresponds to the test of strain rates in the range from $500 \mathrm{~s}^{-1}$ to $750 \mathrm{~s}^{-1}$. In addition to the complete port, there are many cracks in the specimen of the third kind of failure mode (multiple fracture mode), which corresponds to the strain rate within the strain-rate range from $750 \mathrm{~s}^{-1}$ to $950 \mathrm{~s}^{-1}$. The main reason why the material does not break obviously at strain rates of $350 / \mathrm{s}$ and $500 / \mathrm{s}$ is that the material does not reach the ultimate tensile strength corresponding to this strain rate. However, at a strain rate of $750 / \mathrm{s}$, the material reaches the ultimate failure strength, and at this strain rate, there is a synergistic time of stress transfer between coating and fiber, and the stress concentration region is mainly located in the middle of the specimen. Finally, after reaching the ultimate tensile strength, the material has a flat fracture. At strain rates of $900 / \mathrm{s}$ and $950 / \mathrm{s}$, while some specimens have tensile failure at the end, there will be more cracks along with it. This is mainly because that the impact tensile time at a high strain rate is very short, about 100 . There is not enough time for the yarns and coatings to achieve the energy minimum state and uniform stress distribution, so that the coating does not deform well with the yarns. It results in the stress concentration in multiple areas and finally develops to multiple cracks.

From the point of view of failure mode, it can be found that different strain rates correspond to different failure modes, and PVC/PVDF membrane materials are sensitive to strain rates. It indicates that there will be many types of failure modes of the membrane structure, when subjected to the impact of wind-induced fragments at different rates. In (1) failure mode, there is no fracture on the surface of the specimens, only a few internal fibers are broken, and there is no obvious cracking in the coating. (1) failure mode mostly occurs at the strain rate of $350 /$ s and 500/s. In the (2) failure mode, the complete flush port appears on the surface of the specimens, and there are no other cracking positions. (2) failure mode mostly occurs at the strain rates of 500/s and $750 / \mathrm{s}$. In the (3) failure mode, in addition to the same complete flat fracture as the $B$ failure mode, there will be more than one incomplete fracture. (3) failure mode mostly appears in the strain rate of $900 / \mathrm{s}$ and $950 / \mathrm{s}$. The specific damage form is shown in Figure 4. 


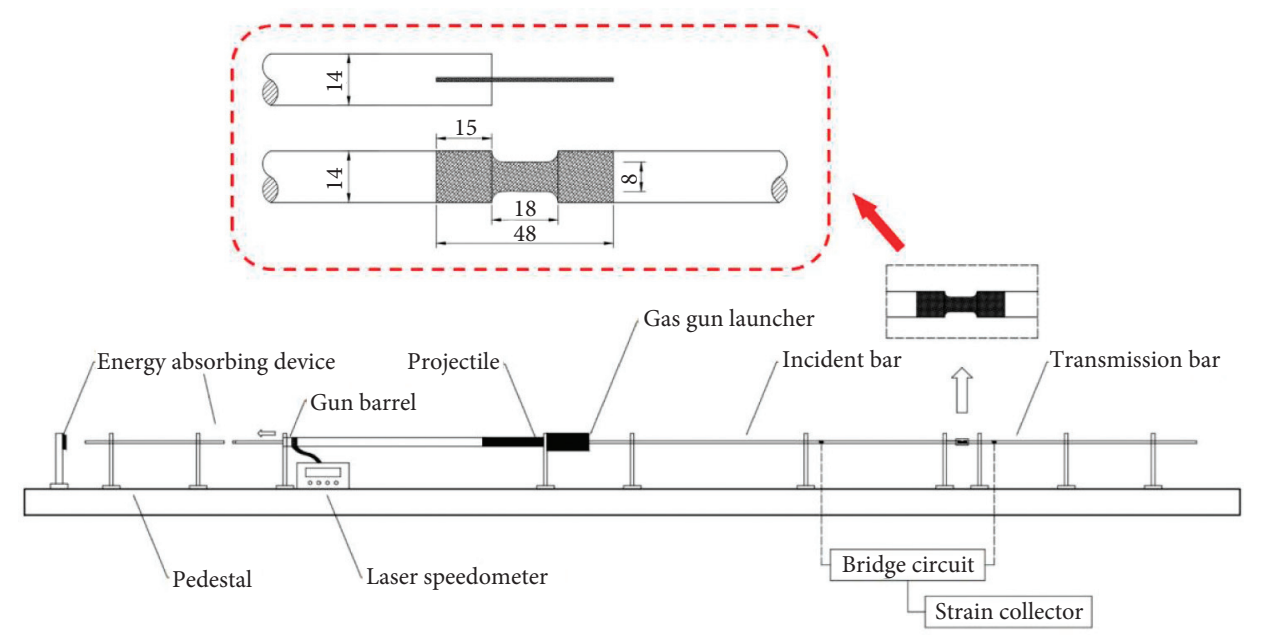

FIgUre 3: Diagram of the split Hopkinson bar test device.

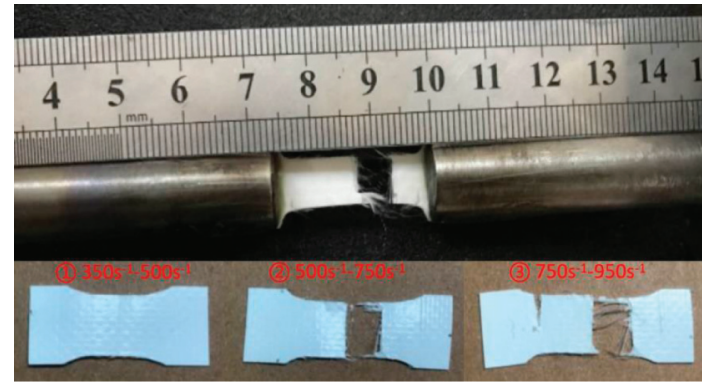

FIgURE 4: Typical failure mode under the strain-rate range.

\subsection{Stress-Strain Relations}

\subsubsection{Typical Stress-Strain Relation of PVDF-Coated Fabrics} under Quasi-Static Tensile Loads. The stress-strain relationship curve of PVDF membrane material under quasistatic mainly consists of two stages, as shown in Figure 5. In the first stage (I), the fiber in the membrane and the coating on the surface are in the elastic stage at the same time, which is shown on the stress-strain curve and approximately shows a linear relationship. After reaching the elastic strain limit, the material enters the stage of plastic stress strengthening (II). In this stage, due to the leading role of fiber stress strengthening, the slope of the stress-strain curve is larger than that of the elastic section, and the stress increases rapidly with the increase of strain. Until the ultimate strain is reached, the specimen is broken.

3.2.2. Typical Form under High Strain Rates. The impact tensile tests were carried out along the warp and weft directions at five strain rates, respectively. According to the one-dimensional stress wave propagation theory [28], the stress-strain curve at high strain rates can be calculated by signals.

A typical stress-strain curve obtained from the impact tensile tests is shown in Figure 5. When it comes to the highstrain-rate state, the stress-strain curves along both the warp direction and the weft direction increase linearly at first.
After reaching the yield point, the increase of the stressstrain curves becomes obviously slower. Then, the stressstrain curves decrease rapidly after exceeding the maximum stress. It can be found that the stress-strain curves are highly sensitive to the strain rate. The impact mechanical properties of PVDF-coated woven fabrics are determined by the mechanical properties of the polyester thread net and the PVDF coating on the surfaces of the woven structure. Since the polyester fiber and the coating material all have high sensitivity to the strain rate, the stress-strain curves of PVCcoated woven fabrics under the impact tension are sensitive to the strain rate.

The stress-strain curve can be divided into three stages:

"Stage I": as shown in Figure 5, point $A$ is the coordinate origin and the starting point. The $A B$ segment is approximately a straight line, which is the "stage I" and becomes a linear stage, in which the stress increases linearly and forms a straight line. The corresponding point $B$ is called the linear limit point, the abscissa $\varepsilon_{\mathrm{b}}$ of the point $B$ is the linear limit strain, and the longitudinal coordinate $\sigma_{\mathrm{b}}$ is the linear limit stress.

"Stage II": point $C$ is the maximum stress point, so the longitudinal coordinate $\sigma_{\mathrm{c}}$ of point $C$ is the tensile strength value of the material, and its abscissa $\varepsilon_{\mathrm{c}}$ is the strain under the tensile strength. The $B C$ segment is "stage II," and the stress value continues to rise after the $A B$ segment, which is called the ascending stage.

"Stage III": point $D$ is the last point of the stressstrain curve, which is called the breaking point, and the strain is the largest. The abscissa of point $D$ is the maximum strain, which is called breaking elongation. The CD segment is "stage III," and the stress begins to decrease from point $C$ to point $D$, which is called the descending section. Then, the curve enters the highest point, which is the impact tensile strength of the material, and then the curve decreases in a straight line, indicating that the material is broken and the material is damaged. 

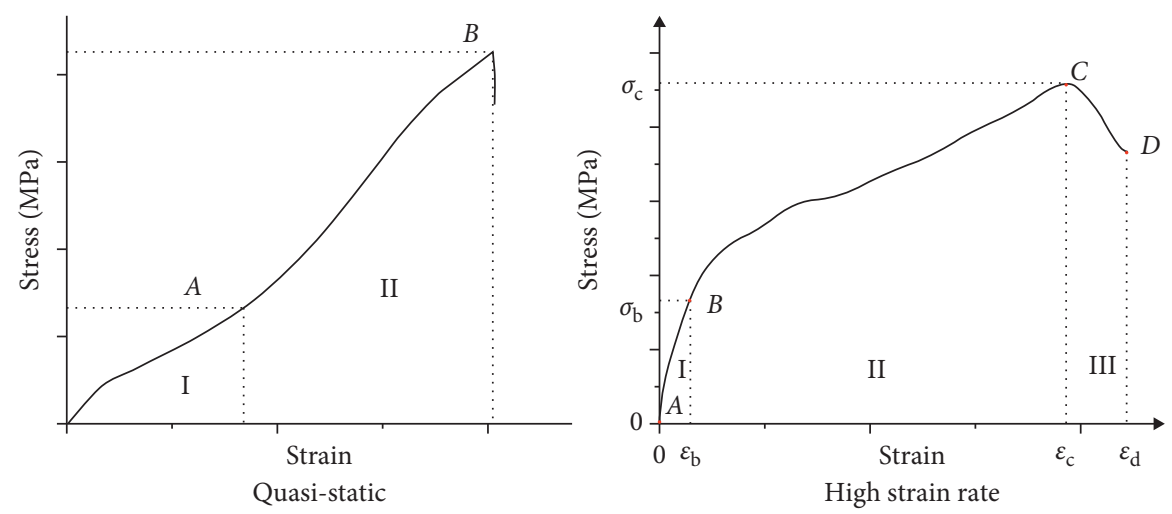

Figure 5: Typical stress-strain relationship of PVDF-coated fabrics.

3.2.3. Stress-Strain Relationship under Different Strain Rates. The mechanical properties of materials under dynamic loads are very different from those under quasi-static loads. In the range of high strain rate, there is little difference in yield stress under different strain rates, which is mainly manifested by the difference of ultimate strength. The ultimate strength increases with the increase of strain rates. Quasistatic loading and Hopkinson bar loading are used as the criterion for distinguishing low and high strain rates. In this paper, the low strain rates are $0.0001 / \mathrm{s}-0.01 / \mathrm{s}$ and the high strain rates are $350 / \mathrm{s}-950 / \mathrm{s}$.

As shown in Figure 6, in the range of low strain rates, the stress-strain curve of the material is approximately coincident in the elastic stage. Within the range of stress strengthening, the ultimate tensile strength of the material increases with the increase of strain rates. In addition, the ultimate strength varies greatly under different strain rates. At the same time, the ultimate strain increases with the increase of strain rates. By comparing Figures 6(a) and 6(b), it can be found that under the same quasi-static strain rate, the ultimate tensile strength along the warp direction is larger, and the tensile strength varies greatly with the strain rate. Compared with the warp direction, the ultimate tensile strength of the weft direction does not change obviously under different strain rates. The mainly reason is the fact that the membrane material is an anisotropic material, and the mechanical properties of warp fiber and weft fiber are quite different. The same conclusion can be obtained by comparing Figure 6(c) with Figure 6(d).

As shown in Figure 6, in the range of high strain rate, the stress-strain curves of the materials in the elastic stage are approximately the same, and the elastic ultimate tensile strength of the materials is consistent. In the yield stage, the stress increases with strain at different strain rates, which is reflected in the slope of the stress-strain relationship curve. However, it is noteworthy that the ultimate tensile strength of materials is different at different strain rates, and the ultimate tensile strength increases with the increase of strain rates. In addition, the ultimate strain increases and changes greatly with the increase of strain rates. By comparing Figures 6(a) and 6(b), it can be found that under the same strain rate, the ultimate tensile strength along the warp direction is larger, and the tensile strength varies greatly with the strain rate. Compared with the warp direction, the ultimate tensile strength of the weft direction does not change obviously under different strain rates.

In the range of quasi-static and high strain rates, stress and strain have a strong strain rate effect with the increase of strain rates. For example, in Figure 6(a), the warp direction of XYD material is in the range of high strain rate, the ultimate strain is $6.5 \%$ at the strain rate of $350 \mathrm{~s}^{-1}$, and the ultimate tensile strength is $57 \mathrm{MPa}$. At the strain rate of $950 \mathrm{~s}^{-1}$, the ultimate strain reaches $23 \%$ and the ultimate tensile strength reaches $88 \mathrm{MPa}$. In the range of strain rate from $350 \mathrm{~s}^{-1}$ to $950 \mathrm{~s}^{-1}$, the tensile strength of the material increased by $31 \mathrm{MPa}$ and the ultimate strain increased by $16.5 \%$. In this process, the ultimate strain and ultimate tensile strength of the materials increase linearly.

3.3. Mechanical Properties. The ultimate tensile strength corresponding to different strain rates is drawn in Figure 7. The ultimate tensile strength of each material increases linearly with the increase of strain rates in the longitude and latitude.

It is noteworthy that there are great differences between the longitude and latitude of XYD materials. When the strain rate increases to the same extent, the ultimate tensile strength of the warp specimen increases more, indicating that the warp fiber has stronger strain rate sensitivity. The anisotropy of ultimate tensile strength of XYD materials is obvious in the range of high strain rate. In the impact resistance design of membrane structures, the influence of anisotropy should be considered. It is suggested that the lower ultimate tensile strength in two directions should be taken as the design value to ensure the overall safety of the structure.

Under different strain rates, the ultimate tensile strength of Ferrari 1002T2 material is similar in longitude and latitude. And with the increase of the same strain rate, the ultimate stress strength increases approximately. It shows that the anisotropy of ultimate tensile strength of Ferrari $1002 \mathrm{~T} 2$ material is not obvious in the range of high strain rate. In the anti-impact design of membrane structures, the materials with similar ultimate tensile strength in two ways under high strain rates are selected as far as possible, so that 


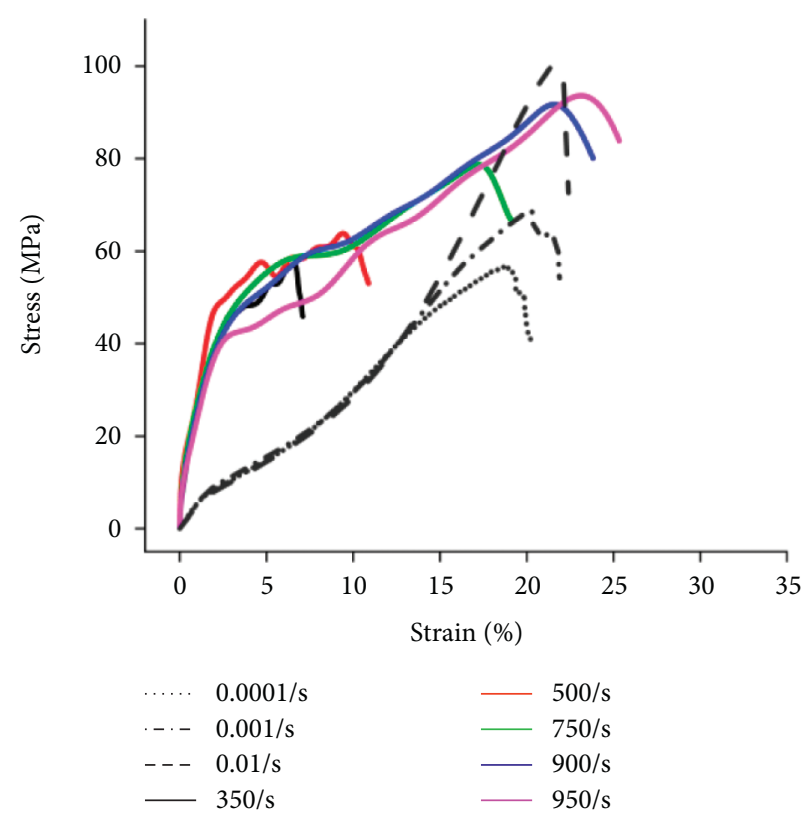

(a)

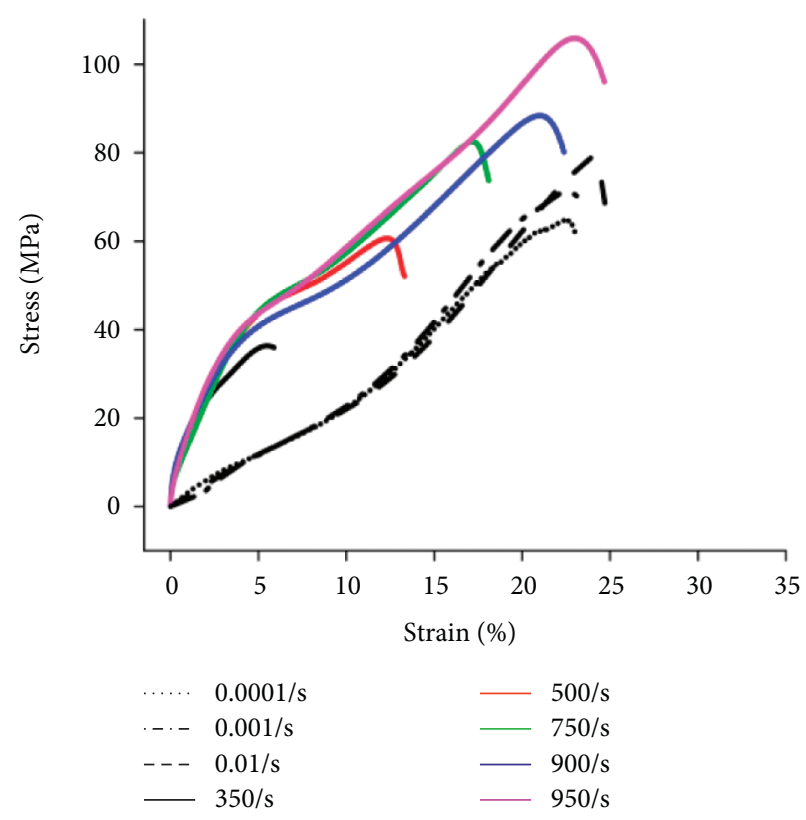

(c)

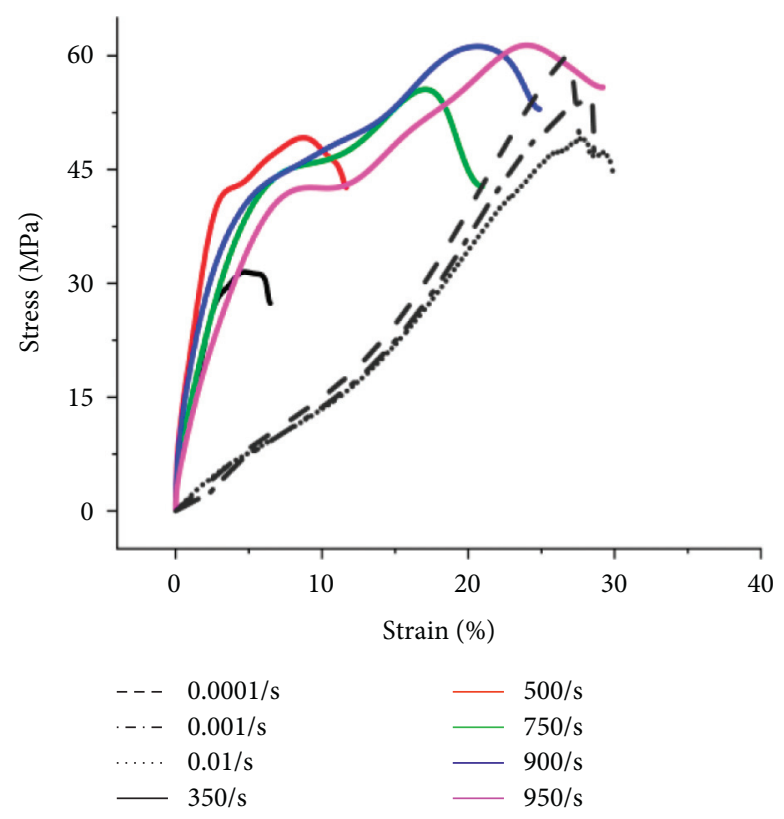

(b)

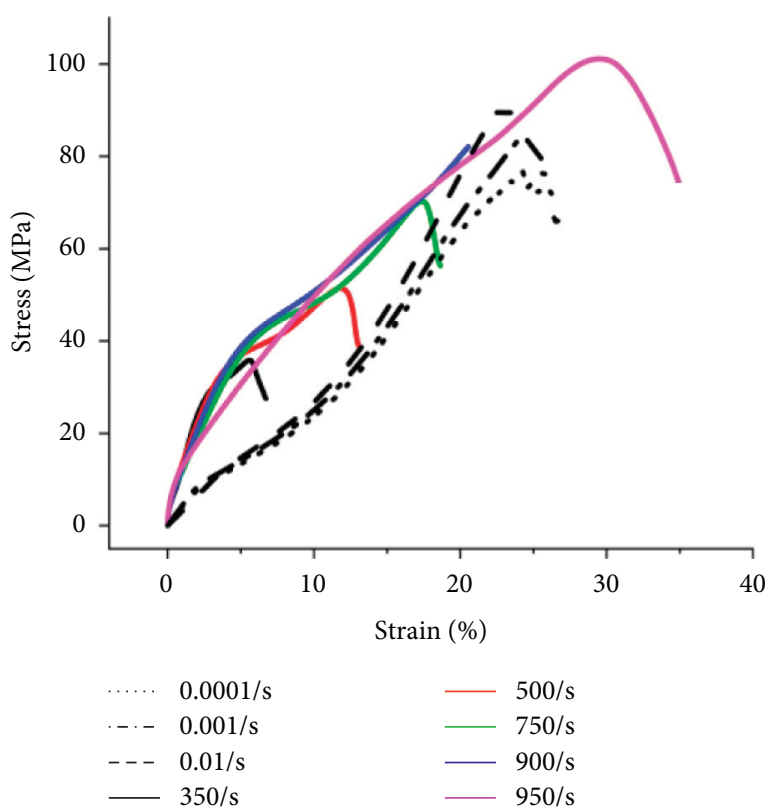

(d)

Figure 6: The stress-strain curves in different strain rates. (a) Warp direction of XYD. (b) Weft direction of XYD. (c) Warp direction of Ferrari. (d) Weft direction of Ferrari.

the material can be fully used to resist the impact of windinduced fragments.

3.3.1. Energy Absorption. Two parameters are used to describe the energy absorbing properties of the two kinds of PVC/PVDF-coated woven fabric. The first one shows the absorbed energy before failure. It can be calculated by integrating the stress-strain curve up to the peak point, as shown in Figure 8. It demonstrates the energy absorbed by the composite before reaching its tensile strength. The other is the absorbed energy, which is the total energy absorbed during the whole tensile process. As shown in Figure 8, the parameter can be calculated by integrating the whole stressstrain curve [22].

Toughness refers to the ability of a material to absorb energy during plastic deformation and fracture process. The higher the toughness, the less the possibility of brittle fracture. The total energy absorbed by the material before it reaches the tensile strength represents the fracture strain energy of the material under the impact tensile load. In this paper, the region surrounded by the coordinate axis and the 


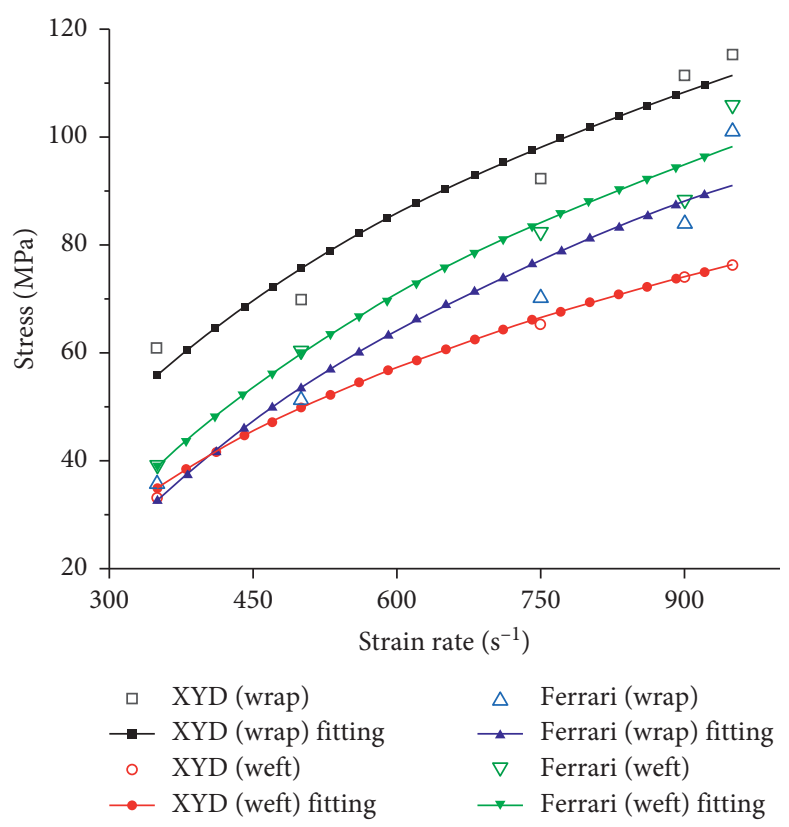

FIGURE 7: Ultimate tensile strength in different strain rates.

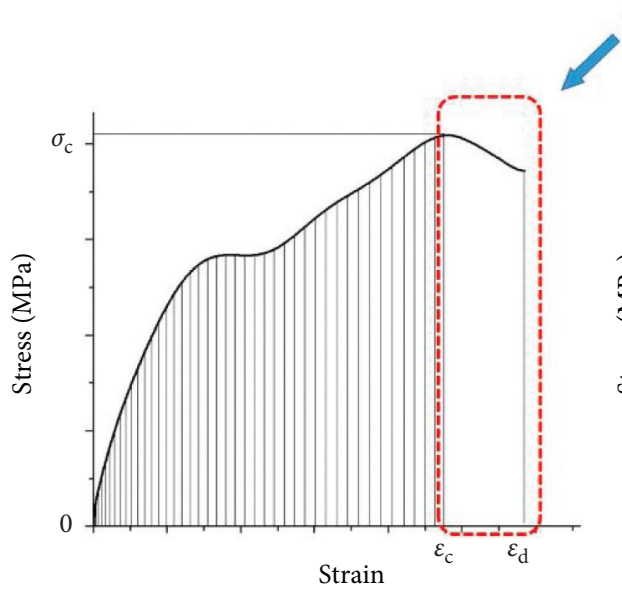

Energy absorption before failure

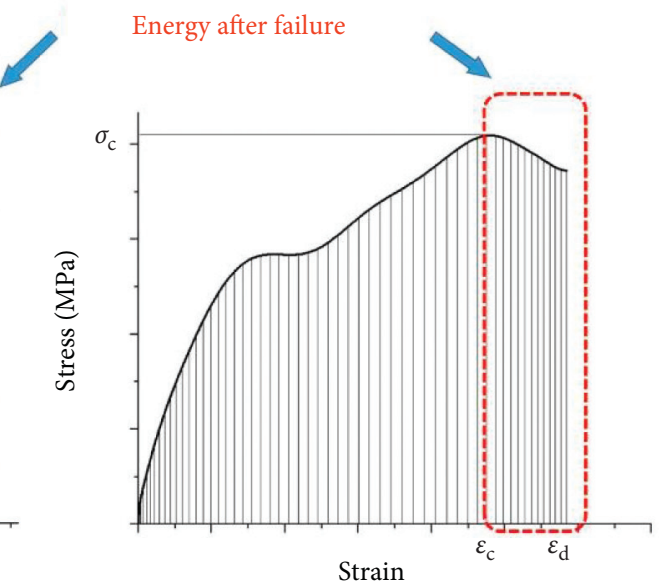

Energy absorption before failure

Figure 8: Energy absorption of the PVC/PVDF membrane.

AC segment in Figure 5 is called the fracture energy density of the material, which reflects the toughness of the material.

According to Figure 9, the fracture energy density of the material increases linearly with the increase of strain rates before the strain rate of $900 \mathrm{~s}^{-1}$, and the trend of PVC/PVDF membrane material is basically the same, indicating that the fracture energy of the material has strong strain rate sensitivity. It shows that the material has better energy absorption capacity and better toughness at high strain rates. It is of great significance for the research of membrane materials as protective materials. At the strain rate of $900 \mathrm{~s}^{-1}$, the warp and weft fracture energy density of Ferrari membrane material change, and the warp direction increases and the weft direction decreases, which is due to the anisotropy of the membrane material.

According to Figure 9, the two parameters of XYD fabric and Ferrari 1002T2 fabric along the two directions increase with the rising strain rate. Significant strain rate sensitivity can be observed. All the phenomenon mentioned above shows that PVC/PVDF-coated woven fabrics have great ability to consume energy in the high-strain-rate state. The absorbed energy before failure along the weft direction of both the two kinds of PVC/PVDF-coated woven fabrics is higher than that along the warp direction, while the difference between the two directions of Ferrari 1002T2 fabric is smaller than that of XYD fabric. 


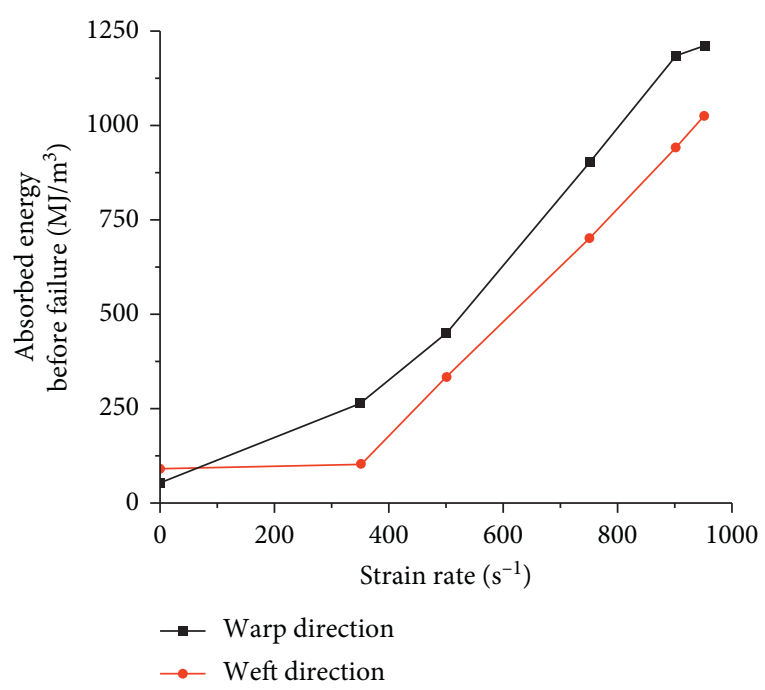

(a)

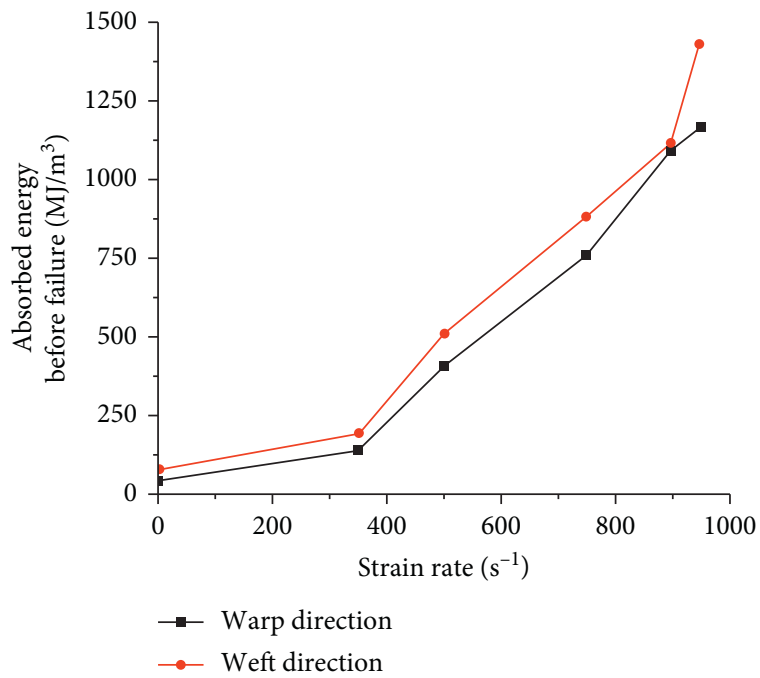

(c)

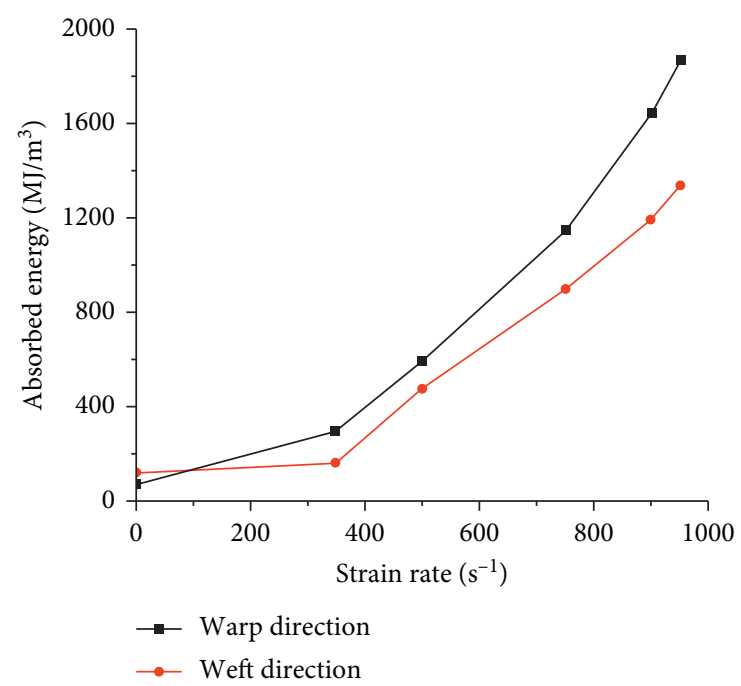

(b)

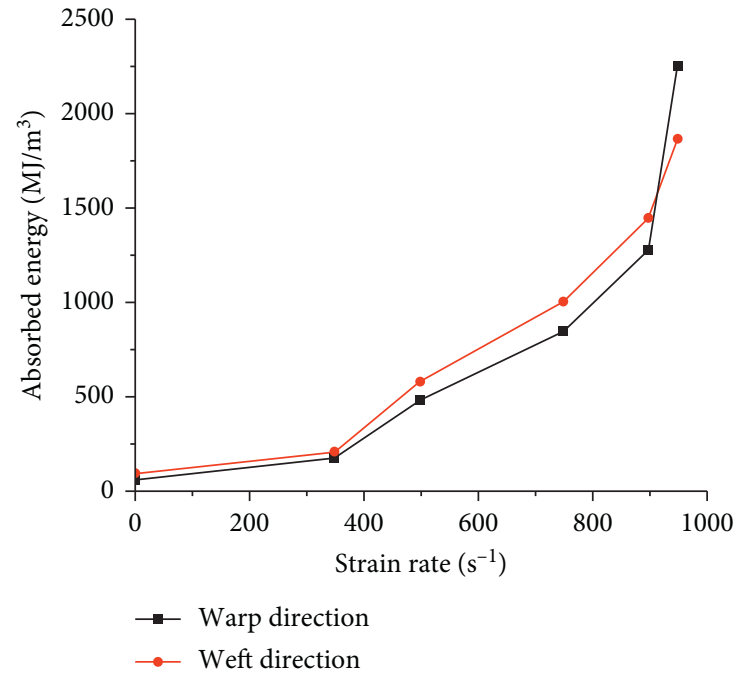

(d)

Figure 9: Energy absorption under different strain rates. (a) Energy absorption before failure (XYD). (b) Energy absorption after failure (XYD). (c) Energy absorption before failure (Ferrari). (d) Energy absorption after failure (Ferrari).

\section{Conclusion}

This paper presents the impact tensile behaviors of PVC/ PVDF building coated fabrics under low and high strain rate. The failure modes of materials under different strain rates are statistically analyzed and the typical stress-strain relationships under quasi-static and high strain rates are proposed respectively. Finally, the stress-strain relationship, ultimate tensile strength, and energy absorption of materials under different strain rates are studied. The following conclusions are obtained:

(1) The failure modes of two kinds coated fabrics are sensitive to strain rates. In the range of high strain rates, there is no obvious fracture in the strain-rate range from $350 \mathrm{~s}^{-1}$ to $500 \mathrm{~s}^{-1}$. The failure mode in the strain-rate range from $500 \mathrm{~s}^{-1}$ to $750 \mathrm{~s}^{-1}$ shows single fracture. The failure mode in the range of strain rate from $750 \mathrm{~s}^{-1}$ to $950 \mathrm{~s}^{-1}$ is accompanied by multiple cracks in addition to the multiple fracture.

(2) In the range of low strain rate, the material stressstrain relationship consists of two stages. The first stage is the elastic stage, and the stress increases linearly with the increase of strain. The second stage is the stress strengthening stage in which the slope of the stress-strain curve increases and the tensile modulus is higher than that of the first stage. In the impact simulation of membrane structures, the constitutive model at the high strain rate is used to describe the mechanical properties of membrane materials, and there is higher displacement in the same strain state, which has the reference value for accurately describing the deformation and damage under the impact loads. 
(3) In the range of high strain rate, the ultimate tensile strength increases linearly with the increase of strain rates, and the ultimate strain increases linearly with the increase of strain rates. In the strain rate range from $350 \mathrm{~s}^{-1}$ to $900 \mathrm{~s}^{-1}$, the energy absorption capacity of the material increases linearly, and the energy absorption increases greatly at the strain rate of $900 \mathrm{~s}^{-1}$. This shows that the energy dissipation capacity of membrane materials under high strain is strong, which provides the energy dissipation contribution of materials to the impact resistance of structures, and the ultimate tensile strength of materials under high strain rates is approximately linear growth.

\section{Data Availability}

The research data used to support the findings of this study are included within the article. Request for more details should be made to the corresponding author.

\section{Conflicts of Interest}

The authors declare that they have no conflicts of interest.

\section{References}

[1] Y. Zhang, Q. Zhang, and H. Lv, "Mechanical properties of polyvinylchloride-coated fabrics processed with precontraint technology," Journal of Reinforced Plastics and Composites, vol. 31, no. 23, pp. 1670-1684, 2012.

[2] J. Hu, W. Chen, B. Zhao, and H. Song, "Experimental studies on summer performance and feasibility of a BIPV/T ethylene tetrafluoroethylene (ETFE) cushion structure system," Energy and Buildings, vol. 69, pp. 394-406, 2014.

[3] W. Chen, H. Hao, P. Irawan, S. Chen, and Q. Meng, "Experimental investigations of fabric material against projectile impacts," Construction and Building Materials, vol. 104, pp. 142-153, 2016.

[4] Y. Zhang, S. Xu, J. Xue, and Q. Zhang, "Anisotropic mechanical properties and constitutive relations of PTFE coated glass fibers," Composite Structures, vol. 179, pp. 601-616, 2017.

[5] X. Junhao, Z. Yingying, and X. Jigang, "Off-axial failure analysis of polytetrafluoroethylene coated woven glass fibers under different loading rates," Journal of Industrial Textiles, vol. 47, no. 3, pp. 310-330, 2016.

[6] Y. Zhang, Q. Zhang, and Z. Yang, "Load-dependent mechanical behavior of membrane materials and its effect on the static behaviors of membrane structures," Journal of Materials in Civil Engineering, vol. 27, no. 11, Article ID 04015018, 2015.

[7] B. Zhao, W. Chen, and J. Hu, "An innovative methodology for measurement of stress distribution of inflatable membrane structures," Measurement Science and Technology, vol. 27, no. 2, Article ID 025002, 2016.

[8] J. Chen, W. Chen, H. Zhou et al., "Fracture failure analysis and bias tearing strength criterion for a laminated fabric," Journal of Industrial Textiles, vol. 47, no. 7, pp. 1496-1527, 2017.

[9] J. Hu, C. Gao, S. He et al., "Effects of on-axis and off-axis tension on uniaxial mechanical properties of plain woven fabrics for inflated structures," Composite Structures, vol. 171, pp. 92-99, 2017.
[10] T. Liu, T. Yao, L. Li et al., "Embedding amorphous lithium vanadate into carbon nanofibers by electrospinning as a highperformance anode material for lithium-ion batteries," Journal of Colloid and Interface Science, vol. 580, pp. 21-29, 2020.

[11] G.-D. Kang and Y.-D. Cao, "Application and modification of poly(vinylidene fluoride) (PVDF) membranes-a review," Journal of Membrane Science, vol. 463, no. 1, pp. 145-165, 2014.

[12] M. Satthiyaraju and T. Ramesh, "Effect of annealing treatment on PVDF nanofibers for mechanical energy harvesting applications," Materials Research Express, vol. 6, no. 10, 2019.

[13] G. L. Oliveira, C. A. Costa, S. C. S. Teixeira, and M. F. Costa, "The use of nano-and micro-instrumented indentation tests to evaluate viscoelastic behavior of poly(vinylidene fluoride) (PVDF)," Polymer Testing, vol. 34, pp. 10-16, 2014.

[14] M. Satthiyaraju and T. Ramesh, "Nanomechanical, mechanical responses and characterization of piezoelectric nanoparticle-modified electrospun PVDF nanofibrous films," Arabian Journal for Science and Engineering, vol. 44, no. 6, pp. 5697-5709, 2019.

[15] T. D. Dinh, A. Rezaei, S. Puystiens et al., "A study of tension fabric membrane structures under in-plane loading: nonlinear finite element analysis and validation," Composite Structures, vol. 128, pp. 10-20, 2015.

[16] A. Ambroziak and P. Klosowski, "Mechanical properties of polyvinyl chloride-coated fabric under cyclic tests," Journal of Reinforced Plastics and Composites, vol. 33, no. 3, pp. 225-234, 2014.

[17] Y. Wang, X. Chen, and R. Young, "A numerical and experimental analysis of the influence of crimp on ballistic impact response of woven fabrics," Composite Structures, vol. 140, pp. 44-52, 2015.

[18] W. Chen and H. Hao, "Performance of structural insulated panels with rigid skins subjected to windborne debris impactsexperimental investigations," Construction and Building Materials, vol. 77, pp. 241-252, 2015.

[19] Q. F. Meng, H. Hao, and W. S. Chen, "Numerical study of basalt fibre cloth strengthened structural insulated panel under windborne debris impact," Applied Mechanics and Materials, vol. 846, pp. 446-451, 2016.

[20] Q. Meng, H. Hao, and W. Chen, "Laboratory test and numerical study of structural insulated panel strengthened with glass fibre laminate against windborne debris impact," Construction and Building Materials, vol. 114, pp. 434-446, 2016.

[21] D. Li, Z. Zheng, Y. Tian, J. Sun, X. He, and Y. Lu, "Stochastic nonlinear vibration and reliability of orthotropic membrane structure under impact load," Thin-Walled Structures, vol. 119, pp. 247-255, 2017.

[22] D. Li, Z.-L. Zheng, C.-Y. Liu et al., "Dynamic response of rectangular prestressed membrane subjected to uniform impact load," Archives of Civil and Mechanical Engineering, vol. 17, no. 3, pp. 586-598, 2017.

[23] P. Ma, H. Hu, Y. Zhang, B. Sun, and B. Gu, "Frequency features of co-woven-knitted fabric (CWKF) composite under tension at various strain rates," Composites Part A: Applied Science and Manufacturing, vol. 42, no. 5, pp. 446-452, 2011.

[24] A. Jain, "Hurricane wind-generated debris impact damage to the glazing of a high-rise building," in Proceedings of the 7th Congress on Forensic Engineering, Miami, FL, USA, November 2015.

[25] B. E. Ross, R. O. Roper, and S. Atamturktur, "Detailing steel roof decks to control damage from wind-borne debris 
impact," Practice Periodical on Structural Design and Construction, vol. 21, no. 1, Article ID 4015010, 2015.

[26] Y. S. Zhao, Y. Y. Zhang, and J. H. Xu, "Frequency domain analysis of mechanical properties and failure modes of PVDF at high strain rate," Construction and Building Materials, vol. 235, Article ID 117506, 2020.

[27] Y. Y. Zhang, Y. S. Zhao, and M. Y. Zhang, "Numerical study on tensioned membrane structures under impact load," Structural Engineering and Mechanics, vol. 71, no. 2, pp. 109-118, 2019.

[28] J. Rong, B. Sun, H. Hu, and B. Gu, “Tensile impact behavior of multiaxial multilayer warp knitted (MMWK) fabric reinforced composites," Journal of Reinforced Plastics and Composites, vol. 25, no. 12, pp. 1305-1315, 2006. 